\title{
GLOBALIZATION: A MIXTURE OF CULTURES AND DISADVANTAGING DEVELOPING COUNTRIES
}

\author{
Lia Maya
}

\begin{abstract}
It is fair to say that the impact of globalization in the cultural sphere has, most generally, been viewed in a pessimistic light. Typically, it has been associated with the destruction of cultural identities, victims of the accelerating encroachment of a homogenized, westernized, consumer culture. This view, the constituency for which extends from (some) academics to antiglobalization activists (Shepard and Hayduk 2002), tends to interpret globalization as a seamless extension of - indeed, as a euphemism for western cultural imperialism. In the discussion which follows I want to approach this claim with a good deal of skepticism.
\end{abstract}

Keyword: Globalization, Culture Studies, Postmodern, Cultural Diversity,

\section{INTRODUCTION}

Postmodern culture, the politics of post-structuralism and the influence of globalization on identity are topics that have received much critical attention and have given rise to complex debates. Whether in the field of cultural and media studies, (post)colonial discourse analysis or aesthetics, these discussions are often perceived as being extremely complicated, confusing or removed from everyday reality. The subject of postmodernism is no longer restricted to learned debates by intellectual elites: Its appearance in mass media discussions concerning topics as diverse as architecture, drama, fashion, literature, music or film has become almost a daily occurrence. The importance of debates on the cultural impact of television is self-evident in the light of television being "an asset open to virtually everybody in modern industrialized societies and one which is increasing its visibility across the planet" (Barker, The Cultural impact of television, 3).

The Cultural Studies in a Global Context fosters cross-disciplinary research and teaching among social sciences and humanities scholars, focusing on the complexities of increasing globalization and intercultural contact. These changes have stimulated both formal and informal dialogues and collaborations among faculty, graduate students, professors of departments, and programs. Recently their works have focused on environmental issues in postcolonial contexts; 
empire, masculinity and gender; ethnic and religious violence; migration and diasporas as it currently occurs in the face of accelerating globalization and from a historical perspective; theories of cultural hybridity and interculturality in the context of asymmetrical power relations; and geopolitical and other kinds of borders where differences of all kinds cause peoples to clash and intermingle.

Two powerful scenarios dominate the public discourse about the cultural consequences of globalization. The one very common scenario represents globalization as cultural homogenization (for example Benjamin Barbers McWorld vs. Jihad). In this scenario the culturally distinct societies of the world are being overrun by globally available goods, media, ideas and institutions. In a world where people from Vienna to Sidney eat Big Macs, wear Benetton clothes, watch MTV or CNN, talk about human rights and work on their IBM computers cultural characteristics are endangered. As these commodities and ideas are mostly of western origin, globalization is perceived as westernization in disguise. The other scenario is that of cultural fragmentation and intercultural conflict (Huntington's Clash of civilizations and most recently "confirmed" by the ethnocide in Yugoslavia).

But can we really reduce the processes of cultural globalization (i.e. the process of world-wide interconnections) to these two stereotypes? What about the meaning that local people attach to globally distributed goods and ideas? Why do people drink Coca Cola and what sense do they make of the soap-operas they watch? Do they really trade in their century old life worlds for the kinds of Madonna and Bill Gates? And how does the homogenization scenario fit with its rival, the imminent cultural fragmentation? (Joana Breidenbach and Ina Zukrigl).

\section{DISCUSSION}

Global and local analysis is inseparability. Global forces enter into local situations and global relations are articulated through local events, identities, and cultures; it includes studies of a wide range of cultural forms including sports, poetry, pedagogy ecology, dance, cities. The new global and translocal cultures and identities created by the diasporic processes of colonialism and decolonization. Cultural studies consider a variety of local, national, and transnational contexts with particular attention to race, ethnicity, gender, and sexuality as categories that force us to rethink globalization itself.

It is very important how local and particular discourses are being transformed by new discourses of globalization and transnationalism, as used both by government and business and in critical academic discourse. Unlike other studies that have focused on the politics and 
economics of globalization, cultural studies, today, articulating the Global and the Local highlights the importance of culture and provides models for a cultural studies that addresses globalization and the dialectic of local and global forces.

\section{Globalization Leads to a New Cultural Diversity}

Culture is one of the most prominent global concepts and gets appropriated in highly diverse ways. From its origins, cultural studies have defined its interdisciplinary impulse as a necessity derived from the nature of its object of study. Stuart Hall locates the origin of cultural studies in the refusal to allow "culture" to be distinguished from the social and historical totality of human practices, as exemplified by the refusal of cultural studies to acknowledge the autonomy of high art from mass or popular culture, or the autonomy of cultural artifacts from practices of reception and consumption in everyday life. Thus globality leads to the emergence of new cultural forms - a process points out that everywhere cultural tradition mix and create new practices and worldviews.

One of the key questions in globalized cultural studies is whether we have now entered a new moment in the institutionalization of cultural studies and interdisciplinary work more generally. Cultural studies also have a long history of skepticism and self-critique directed at its own institutionalization. Typically, the way cultural studies seeks to make its methodologies mirror the "totalizing" nature of its object is cited as a defense against reductive institutional codification along disciplinary lines, which it is feared will not only reduce cultural studies to a formula but also eliminate the interdisciplinary forms of dialogue, collaboration, and critique of disciplinary limits that have informed the history of this movement.

The logic of epistemological mobility and boundary-crossing that cultural studies shares with its definition of culture is supposed to provide an inherent resistance to disciplinary formation, the traditional mode of academic legitimating. The interdisciplinary logic of cultural studies makes possible an alternative mode of institutionalization, so that Stuart Hall distinguishes "institutionalization," as a positive process, from the dangers of "codification." On one level, what a cultural studies program institutionalizes is its own skepticism toward institutionalization as a discipline.

\section{Business Globalization and Economic Global}


Globalization is the ever-increasing process of integration of local and regional markets into one unitary market of products, services and capital. The main results of this process have been an increase in the interdependence of traditionally national markets on the macroeconomic level and the internationalization of corporate processes, especially production, distribution, and marketing, as well as the adoption of international business strategies on the microeconomic level.

Economists recognize the early signs of globalization in historical phenomena, such as the increased economic activity in the Age of Discovery in the 16th and 17th centuries, which led to the founding of the British and Dutch east India companies; and the new economic opportunities enabled by the scientific discoveriesof the 18th and 19th centuries, followed by the 20th century's breaking ground on the Information Age. The World Bank identifies three waves of globalization, which happened between 1870 and the 21 st century. The origins of the process are attributed to the falling costs of transport and the lowering of the politically-driven trade barriers. Trade in commodities developed into trade in manufactured goods. Initially land intensive production became labor intensive. Mass migrations for work became an everyday phenomenon, traveling becoming easier with the development of the more advanced transport technologies. The telegraph allowed more distant countries to benefit from the capital available on the stock exchanges, as stock exchange institutions were brought to new locations, contributing to the growth of financial markets.

Two world wars blocked international trade as individual countries turned protectionist. The situation persisted up till the 1980s, by which time the international exchange between the developed countries was largely freed from the barriers, leaving the developing world outside of the free trade market. It was during the second phase of globalization, when the countries started to specialize in production and the businesses started to function around agglomerations and clusters, that economies of scale started to matter. A discussion on the wealth inequality and the rising poverty in the developing countries started, resulting in the postulates to allow all the nations to participate in the benefit of a free trade. Interestingly enough, the inequalities of the early globalization era in the 19th century were largely related to the ownership of the land, crucial both for the commodity trade and for the manufactures. However, the inequalities during the second phase of globalization showed a more systemic nature, being driven by the protectionist policies of the developed world.

The third wave of globalization brings the "death of distance" in a traditional geographical sense. It does not matter any more whether the whole business process is situated at the same location, as the service and non-core functions, thanks to communication 
technologies, can be successfully performed even on different continents. The third wave of globalization created off-shoring locations in central and eastern Europe and the new, previously developing, economic empires of India and China. Although some of the former developing countries broke their way to the free market and compete successfully for the investments, others remained marginalized and are becoming even more excluded from the benefits of the world economic growth, than ever before. One of the most striking examples of poverty levels and inequality are in the region of sub-Saharan Africa.

The relationship between economic, social, political and cultural aspects of globalization is visible in the main determinants of globalization, which can be attributed to various spheres of human activity. They include but are not limited to digitization, which enables easy distribution of data, information and knowledge paired with a parallel advancement and accessibility of communication channels, especially the Internet; development and internationalization of mass media, which creates certain convergence of consumer patterns (e.g., mass accessibility of TV such as MTV makes the icons of contemporary pop culture such as McDonald's or Barbie the symbols of capitalist world, which developing societies demand, aspiring to the Western style of life; moreover increasing capital consolidation in the sector of media enables the formation of media empires, like Rupert Murdoch's, which allow a relatively small group of opinion-makers to influence whole societies); increasing cross-border and overseas migration trends, caused by people's urge to improve their lives and economic standing; longing for freedom in those countries, which suffer internal oppression either from the ruling class or from any other form of political or economic regime; this enables the democratization political systems and in consequence the introduction of economic liberalization and popularization of the free market philosophy (e.g., the spectacular transformation of central and eastern Europe countries from centrally planned economies to the free market).

Advancing skills of global management allowing entrepreneurs to operate in the wider geographical scale (a new category of companies, called transnational corporations, is both a consequence of globalization processes and a response to increasingly tighter competition, stimulating global dispersion of corporate influence, management methods, production patterns and technologies); convergence of various economic orders toward a free market and liberal economy and, in consequence, a creation of the unified economic model-the only acceptable economic philosophy; technological advancement and dynamics of innovations with their net effects such as a quicker use up of limited Earth resources; this in consequence creates new organizational behavior patterns (i.e., business sustainability, where business models are created on the basis of energy savings and social responsibility); new rules of international labor 
division and, in consequence, creation of geographical competence centers (e.g., information technology [IT] services in India).

Centralization of purchasing by global clients and the economy of scale, which is a direct motivation for global expansion (unit production costs are significantly decreasing with a growing share of B\&R, marketing and promotion costs in a total cost of production); standardization of production and services being a consequence of adopting certain strategies on the global market (a classical example of such standardization is presented by the quality measurement norms-series ISO-certified by independent bodies such as TUV; getting a certificate, which is determined by adopting standard procedures in the organization, often determines whether the company can obtain good contracts as the big companies with large international networks of suppliers and distributors often select partners for co-operation on the basis of quality certificates possessed); less restrictive trade tariffs; strategies adopted by transnational corporations, which aim at gaining more competitiveness on a wider market and which change the rules of labor division as well as internationalization of production process as a result of the complex network of relations between corporate branches in many countries.

Among the strategic decisions of enterprises, two have significant gravity in terms of their ability to force further globalization. First, mergers and acquisitions that contribute to enlargement of organizations per se. Second, off-shoring, or locating some business functions and processes in countries that offer cost reductions without compromising on the quality of the service. Enterprises forced to compete in a tighter and more challenging market seek strategic assets, which are often purchased through takeovers of other companies or through various forms of mergers. Increased mergers and acquisitions activity can be characterized not only by an increased volume of transactions, but also by its significant dynamics (measured by scale of change as compared to the previous year).

It is one of the main stimulators of globalization and a response to more demanding and challenging conditions for competition (companies are looking for foreign markets, which are often less saturated than those of the enterprises' origin, however, as foreign markets accept more players and in due course become a global market, entrepreneurs must compete through taking over the strategic assets). In 2006 the value of assets acquired by purchase or through takeovers reached $\$ 88.5$ billion globally in almost 7,000 transactions. Off-shoring (or nearshoring in the case of locating operations in the countries in a close proximity to the home country) is a strategic trend stimulating foreign direct investments.

Enterprises are largely driven by a paradigm of cost reductions these days. They can achieve it by locating their service functions and non-core activities in the countries that offer 
significantly lower labor costs and a decent level of skills at the same time. Key criteria used in making such decisions are: local economic and political stability, infrastructure, labor market and the level of education, language attainment, and the real estate market. A typical off-shored operation includes call centers and shared services centers, hosting mostly the IT, administration and accounting functions. As such investments bring many new jobs, they contribute to the growth of local economies.

The most competitive locations, in terms of labor costs and overall investment climate, attract great numbers of investments and as the local market saturates, wages start to increase in a natural way- stimulated by the demand-supply situation. At the same time, local governments tend to encourage the investments $\mathrm{i}$ the more complex and sophisticated processes to benefit from a transfer of knowledge and perhaps technologies as well. More sophisticated jobs require higher wages and as the local markets develop toward maturity, as the hosts for off-shoring operations, enterprises move on to the new, less-saturated locations, where they can benefit from the lower costs again. This specific form of colonization is also a part of the globalization loop, where transnational corporations are the reason and the result of the process at the same time. Last but not least, a change in the very nature of competition remains to be mentioned as a key driver of globalization.

Geographic regions compete for resources, for example for the capital and external financing opportunities on the global market. Together with liberalization of capital transfers, new opportunities for obtaining external financing for the projects became available. Companies do not need to apply to banks anymore; they can raise the capital directly on the market, for example through the emission of stock. This phenomena changed the core role of the banks as the sole capital providers. Banking institutions now need to diversify their activity in order to stay competitive. Regions also compete for the investments, specifically foreign direct investments (FDIs), which bring new technologies and jobs.

Globalization should be analyzed in the macroeconomic context-as an aggregated phenomena taking place in the global scale, and in its microeconomic context-at the level of individual enterprises, adopting certain development strategies and making strategic decisions (e.g., locating elements of a value chain in the countries with local advantages or centralizing them in one location). Economic globalization stimulates a significant institutional evolution. Global institutions are set up to manage certain aspects of activity in the global marketplace. They are equipped with both political and economic tools to control and influence the global market players. The most important include the World Bank, International Monetary Fund, and World Trade Organization. 


\section{CONCLUSION}

Our cultural "norms" must be viewed from various perspectives or actions and words get lost in translation. A major factor emphasizing the relevance of workforce diversity to top executives includes the increased importance of global business operations. Companies go global to either acquire high-skilled individuals for increased technical knowledge and skill or to attract low skills associated with low-wage levels. In firms that pursue a global strategy, the higher levels of integration required between affiliate and parent company operations lead to the need for the company to be both globally integrated and locally responsive (Porter, 1986). More work is being done for companies in India, Europe, Asia, and Latin America than ever before. From technology to call centers to document processing what was once only found in the US is now supported globally. And with that support come the need for increased awareness to the laws and cultures of its own associates.

Organizations can take various actions to meet the growing needs of diversity and to address the issue of globalization. Organizations can create an effective diversity program beginning with training at all levels of the organization that would focus on inclusion. Providing "eye-opening" experiences such as temporary assignments in foreign cultures are recommended to help specific employees better understand the challenges faced by others. Mentoring is also important in gaining the full value from a diverse workforce. Succession planning addresses the talent pool at the top of the organization, but employee development efforts must extend down into the organization where diverse candidates are being lost. Midlevel managers and supervisors must be encouraged to identify and develop a diverse pool of candidates. Hewitt needs to identify and develop the human capital that will keep its organization profitable in the global marketplace. Hewitt has always sought to find talented people to fill challenging roles.

The business case for diversity in the workplace--of race, gender, age, ethnicity and more--has been examined and debated over the years. Mary Jo Green explains the rationale behind the diversity initiative, saying that every organization must welcome diversity in order to be successful. "The business world today is made up of a diverse population, and by having a diverse membership, we bring additional viewpoints and talents to the organization, which are 
more reflective of the world in which we operate" (Orenstein, E., May 2005). For an organization to succeed it must not only help its clients but help itself by not just talking the talk but walking the walk. "Some companies truly understand the importance of having a diverse workforce, especially as it relates to the changing face of their customers," said Tapia. "However, for those organizations still not convinced, they should realize that by 2008, minority buying power will exceed \$1.5 trillion, according to the Selig Center for Economic Growth at the University of Georgia" (Preparing for the workforce of tomorrow, 2006).

\section{REFERENCES}

Aprina, C. I. N. I. N. T. A. (2018). Analysis of parenting behavior and adolescent misbehavior at favorite school facing globalization era in Indonesia. Journal of East Asian Studies, (16), 125-141.

Barker, C. (2003). Cultural studies: Theory and practice. Sage.

Barker, C. (1999). Television, globalization and cultural identities (pp. 84-93). Buckingham: Open University Press.

Baylis, J. (2020). The globalization of world politics: An introduction to international relations. Oxford University Press.

Beck, U. (2018). What is globalization?. John Wiley \& Sons.

Devadas, M. B., \& Ravi, B. K. (2013). Cultural impact of television on urban youth-An empirical study. International Journal of Humanities and Social Science Invention, 2(8), 43-52.

Dewi, E. W., Nurkamto, J., \& Drajati, N. A. (2019). EXPLORING PEER-ASSESSMENT PRACTICE IN GRADUATE STUDENTS'ACADEMIC WRITING. LLT Journal: A Journal on Language and Language Teaching, 22(1), 58-65.

Griffin, K. (2018). Culture and Economic Growth: The State and Globalization 1. John Hicks: His Contributions to Economic Theory and Application, 287.

Habibi, H. (2018). PROTECTING NATIONAL IDENTITY BASED ON THE VALUE OF NATION LOCAL WISDOM. International Journal of Malay-Nusantara Studies, 1(2), 24-40.

Kis-Katos, K., Pieters, J., \& Sparrow, R. (2018). Globalization and social change: Genderspecific effects of trade liberalization in Indonesia. IMF Economic Review, 66(4), 763-793.

Melluish, S. (2014). Globalization, culture and psychology. International Review of Psychiatry, 26(5), 538-543.

Pieterse, J. N. (2019). Globalization and culture: Global mélange. Rowman \& Littlefield Publishers. 
Rodrik, D. (2018). Populism and the Economics of Globalization. Journal of International Business Policy, 1(1-2), 12-33. 